\title{
University Centers for the Study of Public Policy: Organizational
} Viability*

\author{
JOHN P. CRECINE \\ Director, Institute of Public Policy Studies, University of Michigan, Ann Arbor, Michigan.
}

\begin{abstract}
The central problems of creating and maintaining a university center for the study of public policy stem from the inherently interdisciplinary nature of the policy design process and the tensions in academic circles between "pure" and "applied" research.

The nature and costs of interdisciplinary communication are such that the unguided, steady state for the organization is a series of disciplinary groups roughly similar to the disciplinary structure of the larger, academic environment. Internal policies and practices designed to maintain interdisciplinary as opposed to disciplinary communications structures are discussed in some detail.

Problems caused by the relationship between "pure" and "applied" research usually stem from a failure to understand their necessary and mutually-reinforcing connections.

The inherently interdisciplinary nature of public policy and the largely disciplinary supply of possible faculty and staff means that, regardless of the internal structure of the particular university the policy unit is located in, the unit is forced to simultaneously maintain a set of relationships with the various disciplines both within and without the university. It is argued that the nature of these external (to the policy unit) interdependencies are the key to the long run viability of the policy unit. The theoretical effects of varying degrees of autonomy for the unit with respect to budget, faculty appointments, and curriculum on viability are examined. Finally, the key role of students in stimulating a meaningful and lasting interdisciplinary dialog among the faculty is discussed.
\end{abstract}

The objective of this paper is to explore some dimensions of the problem of creating and maintaining an organization within a university for the teaching and practice of

* A paper such as this represents a combination of the author's personal experience and background in organization theory. I have been extremely fortunate in having been associated with three excellent, interdisciplinary institutions: Graduate School of Industrial Administration, Carnegie-Mellon University; the Rand Corporation; and the Institute of Public Policy Studies, the University of Michigan. My teachers and colleagues will recognize many of their ideas in this paper. Also reflected are continuing discussions on this topic with GrahamAllison, Otto Davis, John Jackson, James March, Richard Neustadt, Herbert Simon, Aaron Wildavsky, and Sidney Winter among others. Peter Bouxsein and Jack Walker provided insightful comments on an earlier version of this paper. Any lack of perspective is the author's unique contribution. Partially developed analysis in this paper illustrates (unintentionally) the arguments in the last paragraph of section C.1.

Policy Sciences 2 (1971), 7-32

Copyright $(1971$ by American Elsevier Publishing Company, Inc. 
public policy design and analysis. "Policy" and "administration" are seen as ranges on a larger continuum. As used in this paper, the word "policy" refers to the entire continuum, end and means, theoretical concept and delivered service, objective, implementation strategy, and execution. ${ }^{1}$ My remarks on public policy apply equally well to the substance of high level public administration.

\section{Policy Design}

Briefly, this paper views the major task of a university organization for the teaching and study of public policy as involving the design of public policy; the creation of policy and adaptive mechanisms to achieve reasonably well specified objectives in a particular environmental context. The policy design problem includes the design and identification of mechanisms appropriate to particular nongovernmental systems and appropriate to particular sets of environmental constraints. Knowledge of the behavioral characteristics of nongovernmental systems and constraint sets is a necessary component of the design process.

An analysis of the effectiveness or impact of policy can easily be thought of in terms of its relationship to the policy design problem: Is the policy design appropriate? In what ways might the policy be changed so as to better fit environmental constraints or better achieve goals? What are the implications of one design versus an alternative in a specific environmental context? Is the policy meeting its avowed objectives without serious dysfunctional effects? Policy analysis is viewed as a subset of the policy design problem and consequently only the larger question of design will be explicitly considered.

\section{Organization of Paper}

In order, I will first attempt to sketch the composition of the university organization to be examined. This composition gives rise to some internal, organizational considerations such as intra-staff communication. The external relationships of the university public policy organization will then be examined; both intra- and extrauniversity relationships. Finally the long-run viability of such an organization, in light of these internal and external considerations, will be explored.

Composition of a "typical" university organization for the teaching and study of public policy is derived from consideration of the characteristics of an idealized public policy design process. This composition consists of a specification of appropriate ranges of skills and knowledge necessary for policy design and, by implication, the desired characteristics of faculty and staff.

\section{Central Organizational Problems}

From the analysis in this paper, three central organizational problems for the policy subunit emerge: (a) The necessarily interdisciplinary nature of public policy and its design creates an internal problem in communications and intellectual interaction among people with backgrounds in different disciplines. (b) The interdisciplinary

\footnotetext{
1 Although it is not required for our purposes the reader is referred to Dror [3] for a much more
} complete typology.

Policy Sciences 2 (1971), 7-32 
nature of the organization and the lack of sufficient numbers of competent people with interdisciplinary backgrounds creates sometimes costly, sometimes beneficial, dependency of the unit on the several social and management science disciplines or departments within the university. (c) A crucial ingredient in the entire process is a flow of qualified and motivated students. This represents a problem because of the narrow and generally unfavorable view of bureaucracy and administration and the general distrust of government and government-related institutions currently held by the relevant population of potential students.

The three organizational problems will be discussed in the context of the objectives and characteristics of a "typical" university unit for the study and design of public policy.

\section{Is It Possible to Generalize About Policy Organizations?}

No two units for the study of public policy will have identical objectives. No two units will be embedded in the same university structure. Yet I wish to generalize about organizational phenomena in these seemingly disparate settings. My approach is simply to describe a "typical" or idealized unit for public policy studies, based on general notions of the policy design process, and to assume that university structures are similar enough to enable one to identify the relevant dimensions of organizational problems. Obviously the weights attached to these dimensions will vary with actual situations in specific universities. There is some empirical support for the identification of the "typical" and desirable public policy unit in the remarkable similarities among the several new university graduate degree programs in public policy which have emerged since 1967.2 Indeed it would not be too extravagant to say that the study of public policy is finding a major new focus in these emerging programs and that people at different universities are remarkably united on the nature of this new focus. This "common focus" is consistent with the description of an "idealized" university organization for the study of public policy which follows.

\section{A. A Policy Design Process ${ }^{3}$}

The reason for policy, public or private, is to change a current state of affairs into a more desirable one. Although the questions of whose perception of "current" and whose idea of "more desirable" are involved is obviously part of the design problem, we will not treat these as separate topics.

Given dissatisfaction, current or anticipated, with a state of affairs the task of a

${ }^{2}$ At the risk of missing a few, they are (with year of first curriculum plan in parentheses): Institute of Public Policy Studies, The University of Michigan (1967); Public Policy Program, John F. Kennedy School of Government, Harvard (1968); School of Public Affairs, University of California, Berkeley (1969); Policy Analysis Program, State University of New York, Buffalo (1969); School of Urban and Public Affairs, Carnegie-Mellon University (1969); Fels Institute, University of Pennsylvania (1969); Division of Public Administration, Ohio State University (1969); School of Public Affairs, University of Minnesota (1970); Institute of Social Science, Yale University (1970). Similar concentration areas have emerged at many of the larger schools of public administration. In addition, several additional universities are at the proposal state or beyond in formulating programs very similar to those cited above.

3 The careful reader will note the similarity to Simon [6]. 
policymaker or policymaking institution is to invent or otherwise design a means to achieve a better state of affairs; "better" both in terms of reducing or eliminating the source of dissatisfaction and in not creating significant new dissatisfactions in the process. 4 What must be done to create and implement such alternatives? Relatively efficient policy design would seem to involve identification of the relevant factors and constraints from among the noise and complexity of the external environment. Which things must be explicitly considered and which can be safely ignored or assumed constant? What are the costs of violating relevant constraints?

There are many situations where knowing what the "problem" is, is of little operational use in deciding what course of action to follow (e.g., in regard to racial segregation). In addition, a set of ideas or theories is needed to specify, in a loose sense, what a good solution ought to look like.

Knowledge of means under the control of the policymaker and of their social and economic costs is necessary as are procedures for identifying and choosing relatively efficient means to reach or approach a "good solution", from those available. Knowledge of means also includes knowledge of implementation options; bureaucracies, tax incentives, legal restraints, mass education, etc.

Our idealized policymaker obviously needs access to much knowledge and needs considerable problem-solving skills. The policy game is a sequential one with an endless chain of policy moves, environmental responses, policy moves, etc. An appreciation of this fact is also required.

If our objective is to educate a future policymaker, we must not be concerned with only today's policy issues. For instance, the informational and conceptual tools available ten to twenty years from now will bear only a moderate resemblance to those currently available. 5

If our concern is with policy research then we should be concerned with changing the stock of available tools and keeping abreast of changes elsewhere.

With modest translation efforts the above characteristics of the design process would also fit the engineer, architect, composer, auto mechanic, artist, physician diagnosing an illness, computer programmer, or business policymaker. All have the same intellectual task as designers of public policy; the creation of a man-made artifact or system which performs some anticipated function(s) and is compatible with the environment in which it exists.

\section{Two Different Design Problems}

It is the thesis of this paper that much can be learned from the design methodologies of the engineer, et al., in thinking about public policy design. 6 There are some

\footnotetext{
4 I.e., search for a Pareto optimum.

5 For instance, the intellectual revolution brought about by the computer will have (or rather, should have) reached the public sector by the 1980 's. To train people for policymaking roles without the intellectual advantage of computers, as problem-solving and design instruments and as data manipulators, is to build in obsolesence.

${ }^{6}$ I am convinced that this framework sheds significant light on curricular problems for all professional education: schools of law, education, engineering, and business.
}

Policy Sciences 2 (1971), 7-32 
distinctive features of the public sector worth discussing in this context, however. The public sector affects society in two ways:

(1) by direct provision of goods and services (defense, education, garbage disposal, recreational facilities, etc.), and

(2) by intervention in the normal affairs of individuals and societal institutions to change or redistribute outcomes through regulation, subsidization, taxation, criminal codes, etc.

The two policy types represent two quite different design problems. The differences between them involve the relative roles of the environment external to the government or the policy institution. Policies of type (1) have relatively few externally imposed constraints. For example, as long as municipal budgets are balanced and tax levels remain constant, local government can choose, within a wide range, an allocation pattern responsive primarily to internal, governmental requirements. As long as the garbage is collected regularly, few care how it is done. As the past decade has demonstrated, within relatively well defined budgetary constraints, the military can provide defense services in a large number of different ways for long periods of time without much interference from those outside the military establishment. 7 These are easy design problems in the sense that means and mechanisms that produce outcomes (goods and services) are almost all internal to the policy instrument. Relatively little knowledge of the external environment is required for the policy to be effective in the survival or viability sense.

On the other hand, type (2) policies which produce outcomes by intervening in the affairs of nongovernmental institutions and individuals require a great deal of knowledge of the external environment. In such cases, the public sector controls very few of the levers governing the societal mechanisms producing outcomes. Knowing which of these few policy levers to press and how hard requires a great deal of knowledge of the mechanisms as a whole if changes in outcomes are to be those desired. Policy failures due to the lack of understanding of the relevant external environment abound in the areas of foreign policy, military wartime operations, welfare, urban renewal, desegregation, education of people with minority cultural backgrounds, zoning, etc. One of the few real success stories for a policy design involves monetary and fiscal policy and its effects on the national economy. As a society, we can do reasonably well at predicting policy outcomes as long as the mechanism known as the "national economy" is a familiar one. Fiscal policy instruments have been impressively effective when the federal budgetary surplus or deficit has been only moderately large. The response of the economy to the same policy levers has been very sluggish in the face of abnormally high rates of inflation, however. Attempts to use these familiar (Keynesian) economic planning tools in underdeveloped countries have been much less effective-the economic mechanisms which produce outcomes are different from those in the United States, 8 in terms of both structure and parameters.

${ }^{7}$ The federal budget imposes the overall financial constraint on the Defense Department. The President, Secretary of Defense, and Congress are theoretical mechanisms for providing operational constraints.

8 The above observations make it clear that a professional school or research unit involved in public policy, if it is gointg to specialize, ought to specialize on the basis of the behavioral environment 


\section{B. Knowledge Components of Public Policy: Academia}

The above discussion implies that a policymaking body must have knowledge of the workings of the system(s) of behavior in which the objects of policy are embedded (policy environment) and problem-solving skills appropriate to the design problems of creating a policy that adapts to its environment in such a way that the goals of policy are achieved. "Ideally," detailed knowledge of the policy environment would involve highly specific knowledge of each particular environment. Justification for the existence of schools and research centers of social work, public health, natural resources, and urban studies derives from this need for specialized environmental knowledge. However, our objectives are no less than creating a formula for a policy generalist. What knowledge do we have about the general characteristics of systems of behavior in our society? Most of what knowledge we have is firmly deposited in the social science disciplines. General systems theory, a mathematical treatment of the properties of complex systems, ultimately also has much to offer.

\section{B.1. The Environment of Policy: Descriptive Theory}

If policy is to adapt to and operate on the relevant environment in desirable ways we must know something about the relevant environmental systems public policy must deal with. It is not surprising that detailed knowledge of the workings of economic, political, and social systems is found in the disciplines of Economics, Political Science, Sociology, and the Law. To this we must add Psychology and Social Psychology as they involve the study of the building blocks of the aggregate systems-individuals and small groups.

\section{Some Specific Knowledge Components}

The discipline of Economics can contribute knowledge of local and regional economies in urban and regional economics; of the structure and nature of commercial and industrial activity in the subfields of industrial organization, microeconomic theory (especially theory of the firm), and labor economics; and the field of public finance offers a partial picture of the relation of taxation and public expenditures to population characteristics. Aside from providing descriptive theories of how various parts of "the system" work, Economics also has a great deal to offer in providing prescriptions of desirable characteristics for parts of "the system". We will turn to this later.

Political Science contains descriptive theories of the workings of the electoral

\footnotetext{
of the objects of policy. The argument against specialization is that once the requisite skills (people) are brought together for a particular policy area, the set of skills obtained will be appropriate to a much wider set of applications; given changing interests on the part of participants and changing problem priorities, it is shortsighted to artificially restrict a unit's activities to a particular policy area.

9 Implicit in the notion of a special university organization for public policy studies is the justification for such enterprises; to deal with those policy areas not adequately covered elsewhere. Relatively speaking, Economics departments are producing adequate numbers of macrotheorists. Consequently for center of public policy studies macrotheory appears most important as providing a context for the discussion of the workings of other parts of the economic system rather than as a crucial topic in and of itself.
} 
process; of parts of the urban political system; of legislatures; and (all too little) of the legal system. For the most part, Political Science today seems primarily concerned with how governments are formed (elected) rather than the substance of what governments do. There is a growing number of political scientists working on descriptive theories of the policymaking process at all levels of government, with science policy being a growing and important subfield. Most of what is done best in public administration, as a subfield of Political Science, is the study of the role of public bureaucracies in policy formation and execution.

Sociology offers broader descriptions of the social order than the other social sciences being concerned with social stratification schemes and how individuals and social groupings move through such hierarchies over time; with the processes of mass attitude change and public opinion formation; with the structure of large-scale decision systems; and with the nature and process of social change. Professionalization within and in the absence of large-scale organizations is also a major topic of inquiry, as is the study of population or demographic change. All represent environmental phenomena of interest to an "ideal" general policymaker.

Social Psychology and Psychology with descriptive theories of individual and small group decision processes and work-motivation (human relations) theories also provide highly desirable knowledge components.

The Law certainly deserves attention if only because many policy outcomes and external constraints on new policy are legal in nature. How the legal process works in fact versus theory seems vital, especially as our society very recently appears to be shifting its preference for means of solution of social problems towards the courts and away from the bureaucracy. This is especially true in the civil rights area. For instance, environmental pollution has long been a problem assigned to certain regulatory agencies with small staffs and smaller powers. Legislation designed by Professor Joseph L. Sax now allows Michigan residents to sue individuals, corporations, or governments for polluting the environment. This development completely changes the arena (and likely outcomes) for an important class of public problems.

Another vitally important body of knowledge scattered throughout the academic disciplines consists of the largely descriptive theories of organizational decisionmaking and behavior. Components of Organization Theory exist in Political Science, Psychology, Sociology, and Economics. Much work in this field is done in schools of business administration. Almost all public policy either is directed toward large organizations, is administered by them, or both. Organizations form a central part of both the internal and external environments of most public policies; knowledge of the dynamics of the behavior of public and private organizations seems essential. Studies of the centralization-decentralization issue in the context of formal organizations also shed light on these fundamental questions in the organization of all human activity.

\section{B.2. Policy Objectives and Means: Prescriptive Theory}

A category of knowledge as important in the policy process as descriptive theories of how systems of behavior work is prescriptive theories. What are more desirable states for the relevant system? How can one move from the existing state to the more 
desired state? Knowing how the world works may help predict policy outcomes; it is of less use in generating alternative policies, in evaluating outcomes, and in choosing among alternative outcomes (policies). The heart of the design process is in determining what to do and how to do it in the context of a particular policy environment.

\section{Some Specific Knowledge Components}

Notions of desirable workings of a complex system tend to direct attention to and to define policy problems and, in some cases, to suggest alternatives. In Economics, the price system is demonstrated to be an efficient way to allocate resources in a market economy. It is also possible to talk of efficient resource allocation in a nonmarket environment by using this general framework and substituting benefit-cost ratios for prices, etc. Welfare economics also provides a normative approach to resource allocation questions. Planning-programming-budgeting systems (PPBS) represent concrete applications of these normative notions. Topics normally labeled political theory in Political Science deal with the desirable properties of a political decision system as do some aspects of game theory, scattered throughout the social and management science disciplines.

An important set of ideas prescribing desirable ways of choosing among a fixed set of alternatives can be found in statistical decision theory, cost-benefit analysis, and capital theory. These techniques usefully augment the more common advocacy processes for selecting an alternative found in our society.

Management science and operations research focus on techniques for deducing optimal (policy) solutions in situations involving large numbers of variables and external constraints. While private sector applications of mathematical programming techniques have been truly impressive and the ability of many of these techniques to handle the complexity of public sector environments has been demonstrated, much work needs to be done to make these tools more generally useful in the public sector. Primarily, we need to know more about rigorous representation of nonmetric policy variables and the way to specify social and political objectives and constraints in addition to resource and economic constraints.

An "ideal" policymaker should also be able to take large, complex problems and break them into more manageable subproblems. Whether this problem decomposition takes place in the subunits of an organization or in the sequential problem-solving behavior of an individual, it is one of the few demonstrably effective ways we have of dealing with real-world complexity. Social science literature abounds with the centralization-decentralization (problem decomposition) issue. Critical path scheduling and the flow-charting exercises associated with computer programming seem to be among the few easy ways of communicating this skill of problem structuring or decomposition. Work in heuristic programming represents a more formal approach to the same phenomena as do some aspects of set theory and probability theory.

The first stage in the approach to many problems is the identification of additional information needs. Information concerning the processes in a system of a behavior has been covered, implicitly, in the previous section on environmental characteristics. Skills useful in extracting information about the state or status of a system include

Policy Sciences 2 (1971), 7-32 
statistics and survey research. Econometrics is also extremely useful in uncovering relationships among system variables and in verifying process characteristics.

Finally, and perhaps most importantly for would-be practitioners are a set of "people skills". By this I mean the kind of interpersonal skills dealt with in the human relations literature and in sensitivity training. I also include verbal and writing skills as components of "people skills."

People outside of the academic community in policy-relevant positions also represent an extremely important set of knowledge components for a university organization for the study of public policy. These potential members of the organizational coalition will be dealt with later.

\section{B.3. Implications of Knowledge Components}

The list of knowledge components, though reasonably complete, is not meant either to be exhaustive or to represent a minimal set of expertise to be possessed by our university organization. Implicit in the list however is the mandate that both prescriptive and descriptive approaches to policy must be present in the organization; that the mistakes of many public administration programs in only presenting descriptive material be avoided at all costs. Also implicit is the notion of a real balance between prescriptive and descriptive approaches and among the academic disciplines involved.

The list of knowledge components defines the domain of an "ideal" curriculum in public policy and administration, with, at a minimum, a dual emphasis on problemsolving skills (prescriptive theories) and problem-recognition skills and knowledge of the workings of policy environments (descriptive theories). When knowledge is packaged in the form of faculty members, the list provides a guide for a balanced faculty and staff. Particular universities will undoubtedly choose to specialize somewhat within the list. Our general argument has little to say about the direction of any specialization other than:

-specialization by policy environment appears reasonable

specialization should not be at the expense of the necessary balance between prescriptive and descriptive theory

-specialization should not be on the basis of the traditional academic disciplines

specialization in the curriculum, for obvious reasons, ought to mirror the composition of faculty and staff.

\section{Academic Members of the Public Policy Organization-Inter- disciplinary Communication}

It was not necessary to go through the knowledge-components exercise to realize that an organization for public policy studies involves many disciplines. ${ }^{10}$ The number of individuals in the United States who have anything approaching working knowledge in all or even most of the areas listed above can probably be counted on one hand;

10 Although it was useful for identifying the kinds of knowledge within the disciplines that are especially relevant. 
one cannot create a multidisciplinary organization composed solely of interdisciplinary people. Thus, primary sources of members must be the traditional social and management science disciplines: Economics, Law, Political Science, Psychology, Sociology, Industrial Engineering, and Business Administration.

If there is any reason to have a separate university unit for the study of public policy, it is because this unit can facilitate a dialogue between disciplines, both in front of students and in research, that cannot take place in the existing disciplinary organizational structure. The benefits of interdisciplinary communication are assumed; the organizational task for the public policy unit is to minimize communication costs.

Nontrivial communication between individuals is a costly phenomenon in any setting; it is no less so in a university. It takes time and effort even if it is possible at all. In assembling its members a public policy organization can ensure that such communication is possible. In governing its operations the organization can increase probabilities of its occurring. It is doubtful, however, if an organization can, or should, do more than create a favorable environment for interdisciplinary communication.

\section{C.1. Interdisciplinary Communication: Preconditions}

Interdisciplinary communication is more costly than intradisciplinary communication. The reasons why this is so should be kept in mind while assembling personnel for the unit. There are some preconditions for meaningful long-term dialogue between individuals from different disciplines.

(1) Individuals must be able to talk with one another; each must have some minimal knowledge of the other's discipline and they must share, in some sense, a common technical language.

(2) They must have a reason or an intellectual desire to talk professionally to one another; i.e., a common substantive interest.

(3) There must be a mutual respect for each other's intellects, if not their disciplines.

(4) They must personally enjoy the dialogue; communication is, among other things, a social interaction.

Failure to achieve any one of these four preconditions is enough to preclude communication. The implications of these "preconditions" for personnel decisions seem obvious. The necessity for an intellectual desire to communicate implies that an organization should consciously develop centers of research interest rather than people per se while growing.

In general, daily working conditions are as important in fostering communication as personnel policies. For instance, spatial proximity seems absolutely essential. Normal barriers are considerable enough without raising the cost of face-to-face communication prohibitively by having offices scattered over a large university's campus. It has been shown, not surprisingly, that ceteris paribus, a person is more likely to talk to a person next door than a person three doors down the hall. If one wishes to increase opportunities for interdisciplinary contact, one way is to periodically change office assignments.

Policy Sciences 2 (1971), 7-32 
It is important to realize communication costs are relative; i.e., to achieve a reasonable level of interdisciplinary communication one should keep the costs of interdisciplinary communication within range of the costs of disciplinary communication. Subunits within the public policy unit organized around academic disciplines would raise the relative cost of interdisciplinary dialogue and therefore should be avoided at all cost.

Finally, it takes time to exchange nontrivial thoughts, especially when they are not familiar. This time must be made available. University organizations, when faced by a problem usually appoint a committee to solve it, or delegate increased administrative responsibility to a faculty member, etc. The net effect is that administrative dialogue replaces intellectual dialogue. When decisions are made that affect a faculty member's time there is an equally direct effect on time available for intellectual dialogue. The ideal solution of course is to explicitly budget time for this activity'11 (research appointments to compensate for the higher cost of interdisciplinary communication, interdisciplinary teaching assignments, seminars, etc.). Minimizing nonintellectual dialogue maximizes the probability for intellectual dialogue and vice versa. The current trends in American universities all seem to affect time for scholarly communication in a negative way and this raises significant doubts as to whether a university is the optimal setting for a center of public policy studies.

\section{C.2. Substance and Form of Interdisciplinary Communication}

Before moving on, it may be useful to comment on the nature of desirable interdisciplinary or multidisciplinary exchanges. ${ }^{12}$ For instance, it is usually assumed that when two people from different disciplines collaborate on research, it is desirable that they somehow incorporate each other's ideas and perspectives into a larger conceptualization of a topic on which a consensus can be obtained. It is generally assumed that all are better off for the exchange and that the consensus set of ideas is somehow closer to the truth. This procedure is not possible in all cases. Even if it were always possible, situations exist where a consensus approach is less desirable than another approach which might be labeled conflict.

The argument for a conflict approach goes as follows. The most meaningful interdisciplinary exchanges take place at the boundaries of the various disciplines, especially where the disciplines overlap and deal with nearly identical topics. Arguments at these boundaries bring out the exact nature of disciplinary perspectives, theories, and variables. The insights and blinders due to the different disciplinary approaches become much clearer to all involved. A sample of topics might be a sociologist and psychologist on social psychology; an economist, sociologist, organization theorist, and political scientist on public expenditure determinants; a lawyer, political scientist, and sociologist on administration of justice; a sociologist, political scientist,

\footnotetext{
11 In my own institution we have attempted to do this through a designation of "quiet days"; days when no administrative activities or outside appointments are the norm.

12 I am indebted to Sidney Winter, Department of Economics and Institute of Public Policy Studies, The University of Michigan, for his ideas on the "conflict" approach to interdisciplinary research and the importance of the interdisciplinary exchange of ideas early in a research project.
} 
and psychologist on political opinion formation, etc. The utility to the scholar of such boundary disputes in sharpening up the essentially disciplinary arguments is generally not realized. Although this essentially defensive posture on the part of all participants is the usual beginning to most interdisciplinary exchanges, most scholars view this as an indication of failure, withdrawing from the debate with hurt feelings and an implicit denouncement of the other discipline(s). The "conflict" approach, like the "consensus" approach requires the same communication preconditions mentioned above (perhaps more so) and a realization that constructive conflict is also a desirable and expected outcome of interdisciplinary exchange.

As any member of academia knows, the ego involvement of the practicing researcher in his research is a significant barrier to flexibility and, consequently, to meaningful contributions to his work by people outside of his discipline. For this reason, the intellectual inputs of others should be obtained before too much ego involvement takes place; when a research project is still in the half-baked-idea state. ${ }^{13}$ Half-serious seminar discussions and very informal memos for-internal-distribution-only are what I have in mind-more than a general brainstorming session on a topic and much less than a prepublication draft or polished seminar.

\section{C.3. Organizational Implications of Interdisciplinary Communication Characteristics}

As has been argued above, the success of organizationally supported interdisciplinary exchange depends on the preconditions for interdisciplinary communication. The discussion also implies a rather tightly knit group of people, with a great deal of continuity in organization membership. To achieve a level of exchange comparable to that in a traditional academic department would seem to require a more closely knit group (in a social sense) than that in a department to offset increased communication barriers. An organizational form emphasizing joint appointments of a one- or two-year duration and no budgetary guarantees for at least semipermanent membership in the public policy organization is clearly inappropriate; this category includes most of the older research institutes and centers of government and public administration in the country and is one reason for their general weakness.

One final comment on the communication problem is called for before proceeding. If the university organization for the study of a public policy has an educational program, this fact provides an extremely important reason for being concerned about the level of interdisciplinary exchange among faculty. The fact of an educational program, interdisciplinary in nature and with some pretensions of internal coherence, forces a great deal of relevant communication among the teaching staff. In many respects common curriculum design problems aid the development of mutual respect, knowledge of the substance of other disciplines, and the like among the faculty and serve as a useful prelude to more intense interactions. Students function

\footnotetext{
13 This section is borrowed from experience with our Half-Baked-Ideas Seminars and Smirking Paper Series (as opposed to our Working Paper Series) at Michigan. The norm is one of minimal preparation, polish, and ego involvement.
}

Policy Sciences 2 (1971), 7-32 
as a vital link in the organization. For these reasons I would strongly recommend a teaching program coupled with any public policy research operations, if only on the basis of the force it represents for the organizational cohesion necessary for research activities.

\section{Nonacademic Members of the Public Policy Organization}

For educational and research purposes, direct contact with actual policy issues and environments is essential. Both as a source of insight into the workings of the real world of policy and as a source of problems and data, a public policy organization needs to count practitioners among its members. It is not important whether these people are "in-and-outers," high-level officials on leave for a brief period in a university, academics with significant policy experience, or individuals in policy and administrative positions who have long-term contact (perhaps a consultive relationship) with individuals in the organization. What is important is that this intellectual capital be available to the organization, its students, and its faculty. Presumably the organization will also have something to offer people in policy and administrative positions as sources of knowledge, ideas, new perspectives on old problems, personnel in the form of program graduates, and the like.

Inclusion of nonacademic members in an academic organization generally raises an issue best described as academic snobbery. In the social science disciplines at least, practitioners are generally held in some intellectual disrepute. This results in large part from the feeling of intellectual superiority (which is not particularly well founded) on the part of academics and is part of the intellectual bias against applied (versus pure) research. Both general biases are due as much, I believe, to ignorance and lack of exposure as to deep-seated attitudes. One well-chosen individual can do much to dispel this situation internally. At the risk of sounding like an intellectual racist, however, it seems prudent to assess the attitudes of other university units in choosing the appropriate ratio of people with nonacademic backgrounds to include as full-time participants in a policy study organization.

The seeming distaste of most social science academics for applied or serviceoriented research has, in my opinion, a strong empirical basis. Most applied research is simply not intellectually sound, lacks rigor and reproducibility, is often done for purely economic motives, often involves people who simply cannot "make it" in academe, often is designed to suit the preconceptions of the receiver rather than the dictates of the problem, and generally does not lead to additions to knowledge, applied or theoretical. All too often, those who do applied research in a university are treated as second-class citizens. Unfortunately this status is usually deserved.

\section{E. Applied versus Theoretical Research}

There is nothing inherent in the nature of applied research, which forces it to be inferior to pure theoretical work. On the contrary, one can make a very strong argument that applied research provides necessary impetus for productive theoretical research by allowing reality to pose the relevant theoretical questions. 
Kuhn [5] has forcefully argued that, consistent with the scientific method myth, major theoretical breakthroughs in science can usually be traced to situations where theory proved inadequate to account for empirical phenomena. Inconsistent with the myth, however, is Kuhn's argument that the reason the structure of theory does not always mirror the structure of reality is the reluctance of scientists, physical and social, to discard existing theoretical structures even after repeated empirical failures. It is the force of intellectually vested interests that leads science down long and incorrect paths, creating the opportunity for those major scientific revolutions that correct the situation and change people's world views. That preconceived notions (theories) have costs as well as benefits in the "search for truth" is hardly surprising. The message is simply that good theoretical or pure research cannot take place, especially in the policy sciences, without concurrent applied research. Both seem necessary, and both kinds of activity have a place in an organization for the study of public policy.

In theory, applied research is necessary and also, potentially, involves as much or more rigor as basic research. Yet a public policy organization must ensure against low quality applied research to establish and/or preserve its standing in the academic community. One built-in quality control is to insist that all applied research actually consist of the application of an explicitly stated "theory"; that every applied project have an explicit theory component to it. This usually means avoiding most strictly contract work with governments who insist on paying for only what is immediately useful to them, and explicitly including a theoretical component in all proposals submitted to outside agencies. Perhaps the best insurance of "good" applied research however involves hiring faculty members who for reasons of mobility, rank, salary, and personal commitment have scholarly values consistent with those of the academic disciplines. Academic disciplines can and should share directly in the maintenance of intellectual quality of the public policy organization.

\section{F. Relations with Other University Units}

Perhaps the most intractable of the problems facing a university group for the study of public policy has its origins in the structure of academia in the United States. Knowledge and people are organized by disciplines. If a faculty member advances, in academia, it is through his discipline. His job mobility and status are almost always governed by his discipline. For the individual, membership in an interdisciplinary organization brings with it the risk of being cut of from his reward structure and eliminating his job options. Assuming that most members of university organizations for the study of public policy see their careers as being in academia, it is clear that the fledgling public policy organizations can offer no acceptable substitute for the disciplinary reward structure. If inclusion of social and management science skills is essential, as we have argued above, then consideration of the relationship of a public policy unit to these traditional disciplines is of prime importance.

Regardless of the characteristics of the particular university, disciplines must be dealt with, due to their importance in the lives of potential policy unit members. There

Policy Sciences 2 (1971), 7-32 
are two extreme types of university organizations; ones without strong, semiautonomous administrative structures organized around disciplines (e.g., University of California, Irvine; Carnegie-Mellon University) and those with strong, semiautonomous units based on disciplines and a full complement of professional schools (e.g., University of California, Berkeley; Harvard University; The University of Michigan).

What is at issue here is the feasible and desirable degree of autonomy with regard to the social and management science disciplines for a unit of public policy studies. Because the larger career objectives of individual faculty are organized around disciplines, I argue that pressures will always exist for close ties with a man's home discipline. Even in organizations with no formal affiliations with a discipline, pressures will exist to establish such affiliations. Two brief examples will illustrate my point. The first concerns a school embedded in a university with no social science departments. Although for the first two decades of its existence it maintained a unique and excellent reputation for highly quantitative, interdisciplinary research involving the social and emerging management sciences, its more recent history shows a gravitation in fact, but not in form, toward a departmental structure with economics, management science, and social psychology being the "departments." Throughout its existence this school has experienced an unusually high turnover among its faculty, partly attributable, I think, to a reluctance among many to being "cut off" from their discipline for too long. The second example involves a large interdisciplinary social science school in a new university with an explicit policy against disciplinary departments. Pressures emerged very soon after its founding, especially among the younger faculty, for disciplinary committees or the like. Even in universities without disciplinary units, I would contend, pressures exist to reduce the autonomy of an interdisciplinary unit with respect to the disciplines, usually by establishing disciplinary departments within the unit. Even if these pressures are resisted in a formal sense, they manifest themselves in high turnover rates. I suspect the number of interdisciplinary units involving the social and management sciences that could effectively resist pressures for close, formal ties with disciplinary departments is on the order of five to ten-primarily on the grounds that it takes a great deal of self-confidence and commitment to an interdisciplinary ideal to cut oneself off from one's discipline. Not many such people exist. Perhaps the time will come when one can move as freely from one interdisciplinary institution to another as from one disciplinary unit to another. That time, at best, is a long way off.

The more usual case would seem to involve the establishment of a public policy unit in a university with existing social and management science departments. Relations with other professional schools present another problem, to be dealt with later.

\section{F.1. Inherent Interdependency}

If we assume that the kind of academic we want for membership in the policy unit is someone good in his discipline who also has public policy and interdisciplinary concerns, I argue that it would be nearly impossible to recruit such a person if he did not think he was acceptable to the disciplinary unit in the university as well as to the 
interdisciplinary one. Whether disciplinary approval is explicit in the form of a joint appointment or implicit is of much less importance than the approval itself in some form. The costs to the policy unit are a loss in autonomy, continual pressures on faculty to be strictly disciplinary, and in the case of joint appointments a danger of losing the man's commitment to the disciplinary unit. The benefits, aside from the internal, bureaucratic ones associated with a good working relationship, relate to the quality control functions the disciplines perform with respect to both initial appointments and research. The benefits to the disciplinary unit derive from the increased options available to faculty members making possible a better fit of a faculty member's activities to his interests (faculty morale) and the ability to recruit more and/or better disciplinary personnel than would otherwise be possible. Recognition of the mutual benefits of cooperation, if they exist in specific cases, should form the basis of the relationship between the public policy studies unit and disciplinary units.

Intellectually and bureaucratically, disciplinary units have a stake in the activities of a public policy unit in the university. If the disciplines are hostile or even neutral toward the mission or activities of a public policy unit, that unit will become or remain a second-class citizen in the university community. In establishing and maintaining an interdisciplinary unit, in a disciplinary structured university, I would argue that the fundamental determinant of long-run viability is a structure of supportive relationships with disciplinary units.

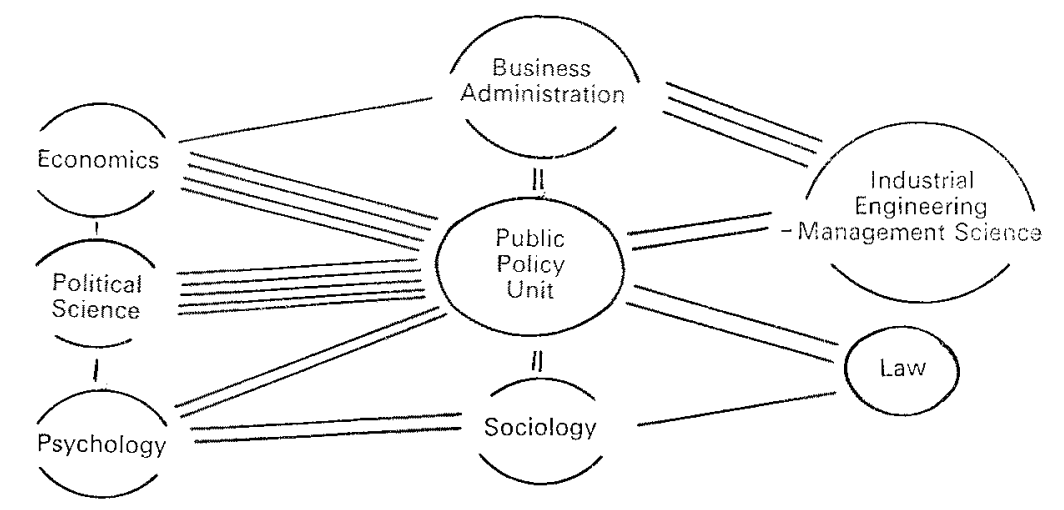

Fig. 1. Necessary interrelationships for public policy unit.

Establishing and maintaining such relationships is a task of some magnitude. Consider the sociogram in Fig. 1. The number of lines connecting two units might represent the numbers of faculty with joint appointments and hence the strength of association. The task of the public policy unit is no less than continuous, simultaneous maintenance of all the supporting relationships. In the somewhat oversimplified diagram, there are seven units intimately involved in the unit's activities. If satisfactory relations with all units are vital for a well-balanced program, it is clear that the chances of something going wrong are high. 


\section{F.2. Necessary Autonomy-Interdependency Balance}

There are several dimensions to the autonomy question. The three that seem to capture most important considerations are: form of faculty appointment, financial relationships, and curriculum control. For purposes of analysis of alternative organizational forms define each of these variables to be two-valued.

Faculty Appointments:

-Joint; policy unit shares salary costs with disciplinary unit. Ultimate responsibility for salary and promotional decisions rests with disciplinary unit.

-Independent appointments made by public policy unit which also has ultimate responsibility for salary and promotional decisions.

Financial Arrangements:

-Budget a composite of outside funds from contract research, with some regular university support, and institutional development grants (soft funds), volatile financial situation.

- Budget largely consists of regular university funds, considered a normal part of university operations (hard funds), dependable sources of funds.

Curriculum Control:

-Dependent on courses offered through disciplinary units; policy unit administers program but has control over course content and staffing only at the discretion of disciplinary unit.

-Independent, internally designed and offered course; public policy unit has ability to make teaching appointments, course content, and staffing decisions. We will first consider some of the advantages and disadvantages of each value on the dimensions independently. We will then consider all logically possible combinations (eight) to examine advantages and disadvantages of the various combinations of organizational arrangements.

The advantages of independent faculty appointments are obvious. In the case of newly recruited faculty, the public policy unit has only to find a man to satisfy its constraints and to fulfill its objectives. I have already argued that even with the ability to make independent appointments, an interdisciplinary unit would be well advised to take advantage of the quality control functions disciplinary units perform. This might be accomplished through a system of courtesy appointments, if the disciplinary unit can be persuaded to take its advisory role seriously.

A joint appointment system however raises some interesting and potentially disastrous organizational problems, especially when the financial environment is one of scarcity as it is currently in most universities. Here the interdisciplinary unit is not only asking the disciplinary unit to exercise a quality control function but is also asking it to agree on priorities. For example, should one use the disciplinary unit's limited recruitment budget to obtain a management science type with public sector interests or a development economist, etc.? On the other hand, on the average, it might be that a Joint appointment would enable one to recruit a higher quality faculty.

It seems to be in everyone's best interest to have strong and active participation on 
the part of the disciplinary unit in the quality control function of the public policy unit. This would also argue that all faculty should have at least a courtesy joint appointment. Whether a formal Joint appointment is the prevalent arrangement, even where Independent appointments are possible, seems of less importance and probably is best left to the wishes of the individual faculty member. On the other hand, where serious differences exist between the need priority lists of the interdisciplinary and disciplinary units, some provision ought to exist for making the public policy unit's appointment anyway; an ability to make Independent appointments or in the Joint case, the ability to transfer funds to the disciplinary unit to cover the salary of a particular person.

From the standpoint of program integrity, Hard funds are always preferable to Soft funds. Soft funds usually make it impossible for the unit to make the kind of long-term commitment to a faculty member it expects from him. The communication problem discussed at length above requires continuity that only hard funds can provide. If there is a case to be made for an educational program in public policy, it also is a case for regular university support. The relationship of type of funding to the educational program will be discussed in more detail below. The academic community is filled with negative examples of the effect of contract research on research quality.

If it were possible to piece together a curriculum containing the requisite knowledge components from existing courses in a university without requiring students to go to school for several extra years, most of the arguments for a program in public policy would disappear. In fact, however, disciplinary knowledge and courses are organized (relatively efficiently, I might add) for transmitting and advancing disciplinary knowledge. What is important for a student of public policy is seldom sufficiently concentrated in a single course. In other cases the emphasis is misplaced. For example, a business statistics course may present sequential sampling notions in the context of industrial process control and not, say, in terms of sampling juvenile court records. The key problems in linear programming applications in the public sector are in how to convert and construct relevant variables for a linear programming format and constraint and objective function specifications. In capital theory, choice of the appropriate interest rate is a much more important topic in the public than in the private sector. For all of these reasons, it is mandatory that curriculum content be under the control of the public policy unit. To have control over content means to have control over staffing. In an area without adequate texts, without a tradition, and without an existing body of teaching materials, the usual informal controls of course content found in most disciplines are missing. A coherent curriculum requires close supervision. Whether courses are formally offered through the public policy unit is of no fundamental importance. It should be noted however that a disciplinary unit will always treat the interdisciplinary unit as a peripheral activity and that without substantial control on the part of the public policy unit, the coherence of the program will disappear; without a measure of control, all conflicts get settled in a disadvantageous way. Referring back to our sociogram (Fig. 1), it is obvious why a Dependent curriculum control posture is untenable. The cumulative effects of the inevitable compromises required in a Dependent curriculum status would, in a few years, destroy

Policy Sciences 2 (1971), 7-32 
TABLE 1

Alternative Organizational Forms

\begin{tabular}{|c|c|c|c|}
\hline \multicolumn{3}{|c|}{ Combination } & \multirow[b]{2}{*}{ Comment } \\
\hline $\begin{array}{c}\text { Faculty } \\
\text { appointment }\end{array}$ & Financial & Curriculum & \\
\hline Joint & Soft & Dependent & $\begin{array}{l}\text { Lacks dependable source of funds necessary to } \\
\text { offer the long-run commitments to personnel } \\
\text { necessary to overcome communication } \\
\text { barriers. }\end{array}$ \\
\hline Joint & Soft & Independent & $\begin{array}{l}\text { Unlikely combination of joint appointments } \\
\text { and independent control of curriculum. } \\
\text { Need large supply of soft funds to guarantee } \\
\text { financial support of curriculum and con- } \\
\text { tinuity. }\end{array}$ \\
\hline Joint & Hard & Dependent & $\begin{array}{l}\text { Probably viable as a research organization. } \\
\text { Erosion of curriculum coherence is prob- } \\
\text { able in long run. Funding reliability makes } \\
\text { the necessary long-run personnel commit- } \\
\text { ments possible. Continued renegotiation of } \\
\text { curriculum agreements likely to erode } \\
\text { enthusiasm for program among staff. }\end{array}$ \\
\hline Joint & Hard & Independent & $\begin{array}{l}\text { Viable in long run as a research organization. } \\
\text { Viable in long run as educational program, } \\
\text { especially if participants in the research and } \\
\text { teaching activities are the same. }\end{array}$ \\
\hline Independent & Soft & Dependent & $\begin{array}{l}\text { Unreliable funding increases probability that } \\
\text { ability to make independent appointments } \\
\text { insufficient to make meaningful long-run } \\
\text { commitments to personnel. A small perman- } \\
\text { ent research group with remainder tied to } \\
\text { funded projects may be viable in long run. } \\
\text { Dependent educational program unlikely } \\
\text { to be found in unit making independent } \\
\text { appointments. }\end{array}$ \\
\hline Independent & Soft & Independent & $\begin{array}{l}\text { Same as above. Lack of funds negates benefits } \\
\text { of appointment and curriculum situations. }\end{array}$ \\
\hline Independent & Hard & Dependent & $\begin{array}{l}\text { Viable research organization due to ability to } \\
\text { make long-run commitments. Dependent } \\
\text { educational program unlikely in unit } \\
\text { making independent appointments. Must } \\
\text { guard against cutting self off from disci- } \\
\text { plines and from creating internal, dis- } \\
\text { ciplinary subunits. }\end{array}$ \\
\hline Independent & Hard & Independent & $\begin{array}{l}\text { Viable long-run research and teaching organ- } \\
\text { ization. Must guard against cutting self off } \\
\text { from disciplines and from internal dis- } \\
\text { ciplinary subunits. }\end{array}$ \\
\hline
\end{tabular}


the coherence of any program. The continuous renegotiation of curriculum agreements with all other units involved is bound to erode faculty enthusiasm for the program as well. Because of the relationship of the curriculum to the overall interdisciplinary communications problem it also seems essential to have more or less continuous participation of the same faculty in the curriculum, perhaps rotating course assignments among the group.

To explore the interrelationships between the faculty appointment, financial, and curriculum control dimensions we will next present what seem to be the salient features of each of the eight possible combinations of arrangements. These are found in Table 1.

Basically the observations in Table 1 suggest four organizational forms for a public policy unit that have long-run viability and the chance for excellence in its reaching and/or research programs:

Joint, Hard, Dependent

Joint, Hard, Independent

Independent, Hard, Dependent

Independent, Hard, Independent

The absence of independent control over curriculum content and staffing is seen as leading to an eventual erosion of the coherence in the educational program and to a frustrating and continuous series of negotiations over the curriculum which could easily undermine the research program. Consequently, a Dependent curriculum control status would seem to indicate dropping the educational function altogether, except perhaps to administer a program in which students select from a menu of courses offered in other university units.

From the standpoint of a dual teaching and research function public policy units with Hard funds and Independent curriculum control are seen as viable regardless of the mode of faculty appointment. The problems with Joint appointments can be overcome with financial provisions for making appointments which conflict with disciplinary unit priorities but not with their notions of quality. The problems associated with Independent appointment arrangements (i.e., a school of public policy and administration) can be overcome with strict attention to disciplinary quality control functions and resistance of the internal pressures to create disciplinary subunits.

The four inherently unviable ${ }^{14}$ organizational forms, as a casual survey of existing interdisciplinary units reveals, are either developing toward or are doomed to a state of mediocrity.

\section{F.3. Long-Run Viability}

In the long run the key element of survival for an interdisciplinary unit is the successful maintenance of disciplinary relations. This can only be done by making faculty appointments in the public policy unit that are clearly of high quality in

\footnotetext{
14 Units with teaching and research functions attached to a single discipline lie outside of our analysis. The conditions for viability of these units or of single-purpose research groups are much less severe because of the significantly smaller number of internal and external relationships to be simultaneously maintained.
}

Policy Sciences 2 (1971), 7-32 
disciplinary terms. This means the potential appointee must satisfy two sets of constraints, both the policy unit's set and the disciplinary unit's set. The set of people to choose from who satisfy both sets of requirements is not particularly large. And, even at the present time, the demand is much greater than the supply. If the market were not constrained by disciplinary equity considerations, salaries for this small stock of people would rise, many emerging policy units would disappear or lower their sights, and a few who could afford it would succeed. Spurred by a favorable market, in the long run supply would be expanded. As matters stand now, staffing a quality public policy program is extremely difficult. Creation of sufficient numbers of centers for the study of public policy of a high quality will be highly unlikely if the market is not allowed to operate. This means higher salaries in terms of psychic satisfaction, working conditions, and research appointments as well as in monetary terms.

\section{F.4. Relationships of a Public Policy Unit with Other Professional Schools and Programs}

Relationships with professional schools such as business administration, public health, urban and regional planning, social work, education, law, natural resources, etc., present different considerations than do those involving the social and management science disciplines. In most important respects their educational missions are extremely close to those of a public policy unit. Business and law schools are generally concerned with policy in an environment comparable in breadth to the public sector. Other professional programs chose to focus on a narrower policy environment. As we have pointed out before, if one is going to specialize in the study of public policy, specialization by policy environment makes a good deal of sense. Briefly, there are advantages and disadvantages to both the specialist and the generalist approaches with neither having any inherent superiority.

Without belaboring the point, established business schools are likely to view a new public policy program as something they are equally equipped to do; in many (but not all) respects they are right. There are plenty of examples of the folly of placing a weak public-sector program in a strong, primarily private-sector-oriented institution however. The problem environments of the private and public policy are vastly different; if this difference is not explicitly recognized the policy design (process) suffers.

The specialized policy programs are natural collaborators because of the compatibility of missions. The most natural form of collaboration would seem to be of an ad hoc nature; whenever a seminar or research project in the public policy unit touches on a policy question in the domain of the specialized policy program, attempts should be made to include the relevant professional program faculty. There is always the danger of developing a rival program. It is difficult to conceive of a situation where it makes sense for an emerging public policy program to do so. The possibilities for joint degree programs with other professional schools are great. The inclusion of special concentration areas in the general policy program consisting of courses taken in the appropriate professional school seems like an eminently sensible form of collaboration. 


\section{G. Relationships with Governmental Agencies}

The discussion on problems associated with nonacademic members of the public policy organization covered many points appropriate to this section. I have consciously omitted service from the list of functions. The reason for the omission is that $I$ believe the best service that an academic can perform for a public agency is to do credible research in the domain of the public sector: applied research linked to larger theoretical questions. This however is seldom what public officials see as "service". They tend to view service as helping them with day-to-day problems and with brush-fire situations. This is something academics are ill equipped to do for two reasons: it takes a great deal of time to familiarize oneself with the specifics of a day-to-day situation and to do so on a significant scale would create severe problems for the public policy unit with other (primarily disciplinary) units in the university. Student participation in service activities is another matter. Not that students are initially any better equipped than faculty for the task. They do have more to gain from investing the time to learn the specifics of a real, day-to-day public sector problem, however, and the costs to them in academic terms are much less. Student policy seminars on a particular real governmental problem should provide a mutually beneficial response to public service pressures.

\section{H. Educational Programs and Students}

As I have argued above, the presence of an educational program forces a good deal of beneficial, interdisciplinary dialogue to take place among the faculty in a public policy unit. Any person who has ever spent time on the staff or faculty of a university knows the satisfying and stimulating effects of a challenging student. If my argument concerning the cohesive role of an educational program is even approximately correct, a simple assumption about the positive relationship between teaching satisfaction and the presence of challenging students leads to the conclusion that the presence of a challenging and stimulating student body is a very important factor in determining the long-run viability of an interdisciplinary university organization for the study of public policy. There are some general considerations to be covered regarding the recruitment of quality students. Following that will be a discussion of the characteristics of three types of degree programs; a four-year undergraduate degree, a professional master's, and a Ph.D. program.

The attitudes of prospective students concerning governments in general and government service in particular are what might be described as generally hostile. Regardless of the nature of the degree program, this is a factor to be overcome. Fortunately, the hostility toward government is partially offset by an increased concern for the problems generally dealt with by government: a concern for "relevance". In recruiting students, at this time in our history, it would seem prudent to emphasize the social-problem-solving aspects of a public policy program and to deemphasize the training-of-government-bureaucrats aspect. It would also seem prudent to take considerable pains to point out the nongovernmental career opportunities available 
to public policy program graduates: consulting, private and nonprofit research corporations, administrative positions in nonprofit organizations, staff work in consumer protection agencies (betting on a proliferation of Ralph Nader-type organizations), etc. A social change orientation (revolution from within) will undoubtedly be a more attractive argument than one emphasizing improvement of government operations for the relevant population of potential students. Beyond these obvious measures and the availability of sufficient student financial aid, it is difficult to see what else a single university public policy unit can do to dramatically increase student quality other than by following the time-honored practice of assuming that creative and intellectually superior faculty will, with a sufficient time lag, attract creative and superior students.

\section{H.1. Degree Programs}

By far the most prevalent degree program in both the older public administration programs and the newer public policy programs has been the one- or two-year Master's degree. Very recently, the trend has been to extend the one-year program to two academic years. This trend is in partial recognition of the magnitude of the knowledge and skill transfer task. A brief review of the "knowledge components" sketched out above should provide a convincing argument against a one-year program that purports to be both general and thorough.

The newer two-year master's programs in public policy all have a characteristic mixture of fundamental (disciplinary) knowledge and practice. In the typical program, something over half of the curriculum is aimed at acquiring the requisite social and management science background to examine, in depth, during much of the remainder of the curriculum, real policy and administration problems in the context of supervised policy or research seminars. A program coming after an undergraduate degree poses some unique problems. There is nothing in the common motivations of prospective students that leads to a homogeneous student body. Heterogeneity, no matter how desirable on other grounds, creates rather severe educational problems if one wishes to produce graduates with some degree of homogeneity with respect to knowledge base and analytic or problem-solving skills. Students entering directly from undergraduate programs tend for the most part, to come packaged in two ways: as social science and liberal arts majors impressed by the complexity of the world and its fuzziness, who have systematically avoided work involving mathematics or other types of formal analysis, and as engineering, mathematics, and physical science majors who have acquired an affinity for formal modes of analysis but with little knowledge of social, economic, and political systems. In many respects, the educational task of the public policy unit is to extend the perspectives of each group to include that of the other: to teach people with analytic backgrounds to adapt their skills to a public policy problem environment and to infuse those with the generally less rigorous social science background with some intellectual toughness in the form of systematic modes of thought and analysis. A serious question arises concerning whether it is possible to transform both groups in the same curriculum; e.g., is it necessary to have two tracks? 
A similar problem with heterogeneous entering students has been dealt with by many of the better business schools by simply establishing separate tracts for those who are prepared in mathematics and those who are not. Some of the smaller business schools have simply refused to admit those without a minimum level of competence in mathematics. Difficulties arise in applying rigid admissions criteria in mathematics for a public policy program. Many, if not most people interested in "solving social problems" and hence attracted to public policy programs seem to have developed an aversion to analysis. I will not attempt to show why this might be the case, I merely assert that it is an observable fact. In any event, one can avoid the problem of how to convert those who think analysis is something practiced only by the technician and narrow-minded engineer who cannot see the "big picture," by simply excluding people with no mathematics in their background from the program. Or, the problem can be met head on by exposing students with such feelings to repeated demonstrations of the efficacy of formal modes of thought and analysis in the context of real policy and administrative questions.

Let me carry the analysis of the two, somewhat artificial, student types a bit further. Consider the nature of the self-selection process for the undergraduate engineer. When he decides to enter a public policy Master's program it is a conscious career change. He is interested in the problems of the public sector, but realizes that he must learn some things to which he has never been deeply exposed before. There is an entire body of knowledge "out there" that he is going to have to deal with. He undoubtedly has some hope that what he has already learned will be useful, but knows there is a missing dimension. By contrast, consider the undergraduate social science major. There is a strong feeling that he at least has been working in the "right" area. The problem, as he sees it, is not so much that there are new things he has to learn or new dimensions he must add to his perspective, but rather that he must learn how to apply what he already "knows". If these characterizations are even approximately correct, and I believe they are, the resistance of the social science major to analytic techniques is likely to be much greater than that of the engineer or physical science major to the introduction of social science knowledge. Given the importance attributed to the teaching program of a unit for public policy studies, attention to the above considerations in admission policies and curriculum design seems essential.

The kinds of disciplinary structures that populate our universities, as I have just argued, create the same kinds of communication problems for entering graduate students as for the faculty of a public policy unit. From the standpoint of the objectives of a public policy unit, perhaps it would be useful to consider bypassing the problems of trained incapacity and disciplinary blinders for students by having a terminal undergraduate program in public policy and administration. Most of the topics covered in graduate policy programs are covered in some form at least in undergraduate courses in major universities. There appears to be no reason inherent in the nature of the subject to preclude such an (ambitious) approach. Factors arguing against such an approach are the greater size necessary to support a four-year program, the fact that few students make career decisions early in their undergraduate careers, and perhaps a necessary maturity in judgment that comes with age and that

Policy Sciences 2 (1971), 7-32 
younger students therefore lack. The avoidance of dysfunctional disciplinary perspectives on the part of students may more than offset these disadvantages.

Finally comes the question of a $\mathrm{Ph}$.D. program in public policy. Granted that good doctoral students are nearly essential to hold a good faculty, the question remains whether they should be Ph.D. candidates in Public Policy. Given sufficient research funds, and given the (necessarily) close ties of most faculty to their home disciplines, there is no reason why the public policy unit could not involve doctoral students from other programs in its operations. Very real questions arise concerning where a Ph.D. in Public Policy would find his career. Perhaps programs in public policy will grow at a rate sufficient to absorb Ph.D.'s. Perhaps such a degree would become a valuable credential for potential high-level civil servants or consultants. The important consideration for the long-run viability of a public policy organization is access to high quality doctoral students who wish to work on multidisciplinary public policy questions. If this can be done easily by working through existing disciplinary units in a university, fine. If not, a Ph.D. program would seem to be a very desirable feature for a public policy unit.

\section{Summary}

Two simple arguments form the basis of this paper. The first is that the central internal problems of establishing and maintaining intellectual dialogue between faculty and of carrying out the educational task stem from the inherently interdisciplinary nature of public policy and the unique and necessary blend of basic and applied research characteristic of a professionally oriented program. The problem is that such a combination of disciplines and research approaches, left to its own devices, will seek the same steady state that characterizes the structure of academic institutions in the United States. The environmental forces are all toward separation rather than integration of the blend of disciplines, basic and applied research, and positive and normative theories. Various ways to prevent this "natural" separation have been discussed.

The second argument concerns the great deal of interdependency between a public policy unit and other university subunits (disciplines) in any university setting. Again the difficulties of simultaneously maintaining the multitude of satisfactory relationships necessary for the viability of a public policy unit cannot be overemphasized.

We have argued that the forces of the academic disciplinary establishment are generally arrayed against any inherently interdisciplinary unit. That such a "hostile" environment is no one's conscious wish makes it no less hostile. In order to offset these negative forces, a unit for the study and design of public policy needs strong internal leadership and a self-conscious and explicit attention to the "blending" problems, strong support from the central administration of the university organization within which the policy unit is embedded to resist the leveling influences of disciplinary structure, and continued awareness on the part of the relevant publicsgovernments, academics, and students-of the importance of such an intellectual activity. Survival in these circumstances is by no means assured. 


\section{REFERENCES}

1 Crecine, John P., "A Simulation of Municipal Budgeting: The Impact of Problem Environment," in W. Coplin, ed., Simulation in the Study of Politics, Chicago: Markham, 1968.

2 Davis, O. A., "Economics and Urban Renewal: Market Intervention," in J. P. Crecine, ed., Financing the Metropolis: Public Policy in Urban Economies, Beverly Hills: Sage, 1970.

3 Dror, Yehezkel, Public Policymaking Re-examined. San Francisco: Chandler, 1968.

4 General Systems Yearbook. Ann Arbor, Michigan: published annually.

5 Kuhn, Thomas, The Structure of Scientific Revolutions. Chicago: Univ. of Chicago Press, 1962.

6 Simon, H. A., "The Science of Design: Creating the Artificial," Sciences of the Artificial, Cambridge, pp. 55-83. Mass.: M.I.T. Press, 1969. 